13. Giriraj, B. Prediction of tool wear in high speed machining using acoustic emission technique and neural tenwork [Text] / B. Giriraj, V. P. Raja, R. Gandhinadhan, R. Ganeshkumar // Indian J. of Eng. and Mater. Sciences. - 2006. - Vol. 13. - P. 275-280.

14. Mokhtar, N. Analysis of acoustic emission on surface roughness during end milling [Text] / N. Mokhtar, I. Y. Ismail, M. Asmelash, H. Zohari, A. Azhari // Journal of Engineering and Applied Sciences. - 2017. - Vol. 12, Issue 4. - P. 1324-1328.

15. Filonenko, S. F. Infuencing processed composite material priperties on acoustic emission [Text] / S. F. Filonenko // Eastern-European Journal of Enterprise Technologies. - 2015. - Vol. 2, Issue 5 (74). - P. 60-64. doi: 10.15587/1729-4061.2015.40191

16. Filonenko, S. F. Issledovanie vliyaniya glubiny rezaniya na amplitudnye harakteristiki akusticheskogo izlucheniya pri mekhanicheskoy obrabotke kompozicionnyh materialov [Text]: XI mezhdunar. konf. / S. F. Filonenko, T. V. Nimchenko // Strategiya kachestva v promyshlennosti i obrazovanii. - 2015. - Vol. 1. - P. 134-139.

17. Filonenko, S. Acoustic radiation energy at a variation of the composite mechanical destruction area [Text] / S. Filonenko // Proceedings of National Aviation University. - 2016. - Vol. 67, Issue 2. doi: 10.18372/2306-1472.67.10429

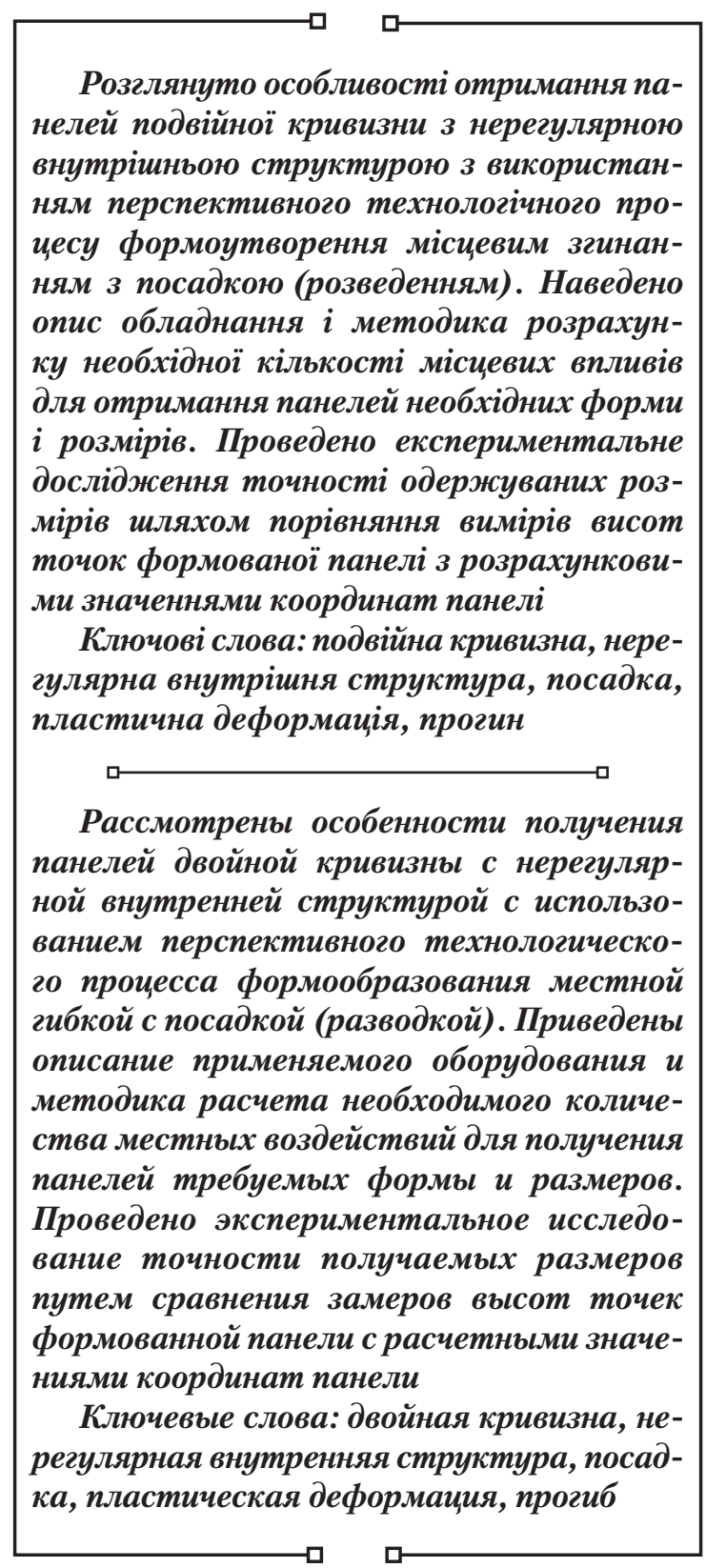

$\square \quad$ 만.

\section{STUDY OF THE PROCESS OF SHAPE-FORMATION OF RIBBED DOUBLE- CURVATURE PANELS BY LOCAL DEFORMING}

1. Introduction

Ribbed panels made in one piece are used in aircraft construction and shipbuilding. They are called monolithic pa- nels. Such panels are obtained most often by rolling or pressing in a flat form. To form panels according to the contour of the product, straightening and refinement of the panel shape, shot peening, free local bending, rolling and other processes 
are widely used. These methods enable obtaining panels of just a small double curvature with nonrigid ribs since they do not provide joint deformation of the panel sheet and ribs. Besides, known methods do not ensure sufficient accuracy and necessary productivity of the forming process. Forming of monolithic panels is a serious technological problem in connection with the tendency of increasing panel sizes. Simultaneously, complication of aircraft shapes takes place which is caused by improvements in aerodynamics. Strength of aircrafts becomes higher, which is expressed in the application of an irregular structure inside the panels. Shape-formation of such panels requires a combination of several known methods for various sections of the panel, e.g. free bending for thickened sections and shot peening bending for sections of uniform thickness. Panels should be formed by highly skilled personnel and the probability of rejects must be minimized because of high cost of the work stock.

Modern aviation structures are designed using computer integrated $\mathrm{CAD} / \mathrm{CAM} / \mathrm{CAE}$ technologies and significant volumes of parts are produced using CNC equipment. However, majority of the manufacturing processes related to forming and shape refinement are performed manually or with the help of such simple devices as free-bending dies which cause serious shaping errors. The main components of the errors in the final panel shape are errors of mechanical processing, the errors caused by internal residual stresses, induced stresses, machining, shaping, shape measurement and the errors of the refinement processes.

In practice, probability of the shape-change errors and the errors of refinement processes is so high that the actual aircraft contours do not always satisfy the design requirements because of their deviations. Therefore, elaboration of a technology and equipment for shape-formation of monolithic panels is a relevant task. Such new technologies should ensure versatility and flexibility of equipment in obtaining various shapes of panels including those with an irregular structure as well as the possibility of automation while improving accuracy of the shapes obtained.

\section{Literature review and problem statement}

Obtaining of double-curvature panels from flat ribbed work stock as well as tapered panels in which direction of the ribs does not coincide with the body generatrix presents the greatest complexity. Fig. 1 shows main types of double-curvature panels, which are widely used in aircraft products: fuselage and wing panels $(a, b)$; bottom panels of hydroplanes and sea vessels $(c, d)$.

Attempts to obtain double-curvature panels were made by many authors despite the problem complexity. Authors pointed out that when forming, it is very difficult to create a stressed state in the panel sheet material with a minimum level of residual stresses [1].

This problem is of great complexity if the double-curvature panels have a variable internal engraving, an irregular cross-sectional structure (including slotted ribs, local transverse thickenings and other elements) [2].

Some authors solved the problem by deforming with heating and it was noted that this method is not applicable for all aluminum alloys since heating to the temperatures of effective deformation reduces corrosion resistance of alloys [3]. Application of drawing processes and other cold working processes is limited because of absence of technological allowances for the panel width, which is connected with the peculiarities of the work stock manufacture. Therefore, recently many authors consider obtaining of a double curvature by combination of local free bending. At the same time, authors point out that when the panels are subjected to deformation, the panel ribs having rigidity much greater than that of the sheet exert a great influence on the deformation process $[4,5]$.
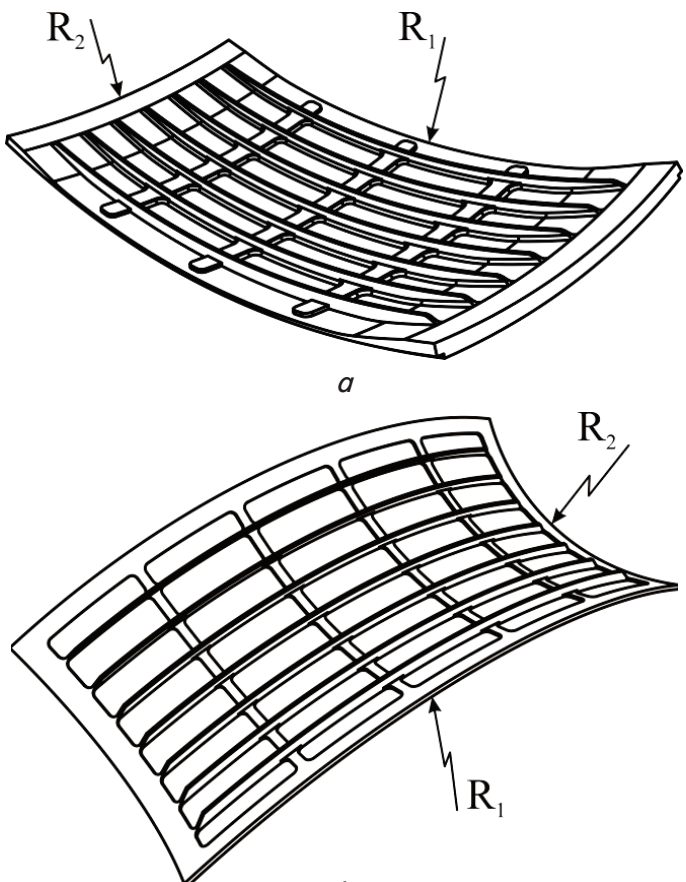

b
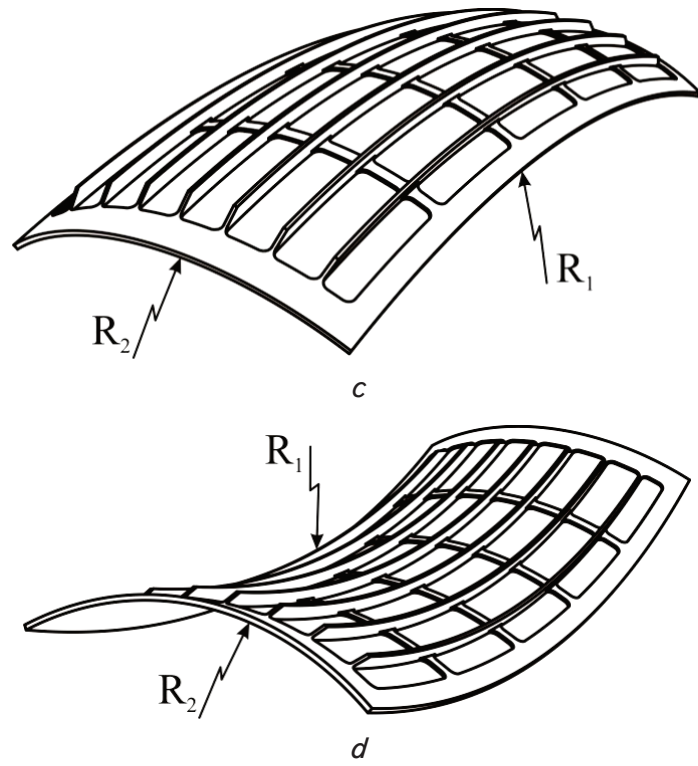

Fig. 1. Main types of double-curvature panels: $a$ - biconvex; $b$ - convexo-concave; $c$ - biconcave; $d$ - concavo-convex

The processes of shot peening forming used in the industry enable production of panels with a single curvature across ribbing or a small double curvature with a ribbing of low rigidity or an intermittent ribbing [6].

Manufacture of double-curvature panels with a complex internal engraving is characterized by a number of features. 
In particular, such panels have various shapes and, therefore, various moments of inertia of the cross sections in the longitudinal and transverse directions. That is why application of conventional methods, e.g. free bending, for shaping such panels is limited or even impossible [7].

Some authors made attempts of exclusion of forming operations, e. g. operations with the use of $3 \mathrm{D}$ printing or metal composite structures [8]. It is known that such technologies require high-cost equipment, which is not justified under conditions of small-scale production.

To form panels including double-curvature panels with an irregular structure, a method of local deformation by shrinking or stretching of ribs together with the panel sheet has been developed by a team of authors [9].

When using the processes of local plastic deformation, it is possible to obtain any local stress-strain state in the zone of force action. As a local action, shrinking (shortening) or stretching (lengthening) of the rib together with the adjacent sheet and simultaneous bending of the area are used to obtain the required curvature.

Forming of panels of required shape and size is carried out by applying a large number of local actions distributed in a certain way [10]. However, until now, forming is carried out more often on the basis of the operator's intuition since there are no reliable procedures for distribution of local actions.

\section{The study objective and tasks}

This work objective was to study accuracy of doublecurved ribbed panels obtained by multipoint local deformation using the proposed procedure for distribution of local actions.

To achieve this goal, the following tasks were accomplished:

- to obtain theoretical dependences of distribution of local actions in a symmetrical shaping of monolithic doublecurvature panels with rigid ribs;

- to conduct experimental studies of accuracy of the manufactured double-curvature panels;

- to test the procedure for calculating the shaping process and formulate recommendations for manufacture of double-curvature panels.

\section{Methods and equipment used in the studies of manufacturing ribbed double-curvature panels by local deforming}

On the basis of the described features, a process and an apparatus for its implementation have been developed in which the panel section is deformed together with the ribs in the jaws holding simultaneously the section of the web and the ribs (Fig. 2). If necessary, the device also enables bending of the panel section together with the rib in its plane. Bending can proceed in both directions, and deformation of the sheet is done by shrinking or stretching. The device is quite versatile and can be used to obtain a variety of panel shapes in a wide range of their cross-sectional sizes. It can be installed in an industrial press with a compacting force of $2500 \mathrm{kN}$ or more. With a small effort, the device provides local straightening and refinement of panels by zonal deformation of the rib in its plane within $10-20 \mathrm{~mm}$. Zonal deformation consists in creating a complex stressed state in a small section of the panel by applying compression or tensile forces together with a bending moment acting in the plane of the rib [10].

Within the framework of the proposed method for forming double-curvature panels, a die design has been developed that enables deforming of the panel sheet together with bending of the rib in its plane (Fig. 2).
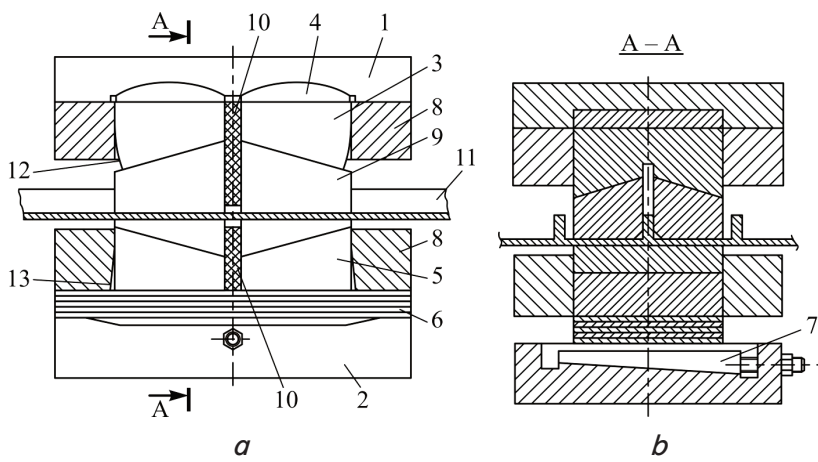

Fig. 2. Diagram of the die for the shape-formation of double-curvature panels with the help of local deformation operations: $a$ - shrinking+bending deformation;

$b-$ the die cross section normal to ribbing

The die structure consists of a top (1) and a bottom (2) plates, a top cage (3), segment inserts (4), a bottom casing (5), a spring (6), a deflection regulator (7), two power frames (8), top and bottom die jaws (9), a shock absorber (10). Local deformation of the panel (11) is carried out by transferring the press force to the top cages, clamping jaws and to an elastic element. Flexure of the elastic element is set by the regulator, thereby creating curvature in the panel section.

In the initial position, the top jaws enable free movement of the panel along the axis of the rib relative to the device that is installed in the press. When the press applies force, the top pairs of jaws catch and compress the panel rib. In this position, the top jaws support the rib during the entire deformation process. As the force increases, the rib is bent in the plane of the rib wall by a set angle. With a further increase in the press force, the left and right, top and bottom jaws converge during shrinking or part during stretching.

The device design provides for implementation of modes of shrinking and stretching, shrinking and stretching with bending in one or other direction or only bending of the panel section in both directions (Fig. 3).

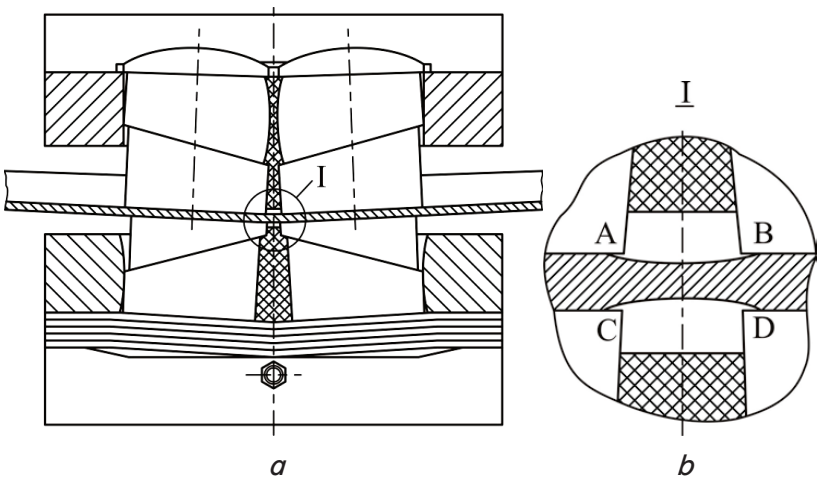

Fig. 3. General view of the device in the stretching position: $a-$ together with bending; $b$ - leader of the deformation zone 
As it follows from Fig. 3, $b$, the deformation zone is not localized in the space between the jaws during stretching but extends over large distances $A B$ and $C D$. On the contrary when shrinking takes place, there is localization of deformation in the area between the jaws, in this case the distances $A B$ and $C D$ are equal to the distances between the right and the left jaws. Therefore, the use of swaging during shaping makes it possible to obtain large elongations at lower strain values in comparison with shrinking. For this reason, the use of swaging should be considered more preferable for shaping.

\section{The procedure of distribution of local deformations}

The essence of the process of making a panel of a complex shape consists in the step-by-step imparting of a generalized field of deformations to the panel. This field consists of a number of separate local deformations. The local deformations should be distributed in a certain way both across the panel area and in the time of their application so that the generalized deformations correspond to a gradual approach to the desired shape of the panel. Local actions should be distributed evenly along each rib with a step determined depending on the transverse and longitudinal radii of the panel curvature. Distribution of local actions during forming of a biconvex shaped panel is shown in Fig. 4.

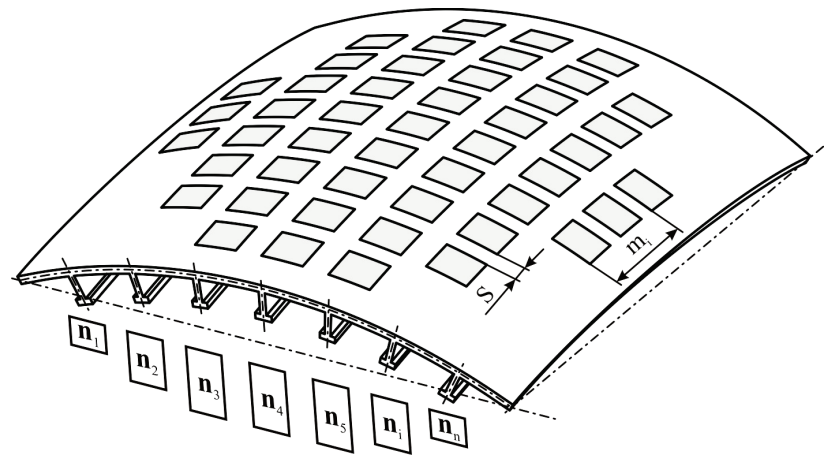

Fig. 4. Schematic of distribution of local actions in forming a biconvex panel curvature: $S$ is the dimension of the deformed section of the panel along the rib axis at a single technological action; $m_{i}$ is the distance between two adjacent points of action in one rib; $n_{i}$ is the number of actions in one rib

Consider the process of shaping from the position of sequence of applying actions. Let the panel shape be achieved by applying deformations along the $x$ axis as shown in Fig. 5.

Deformations are applied sequentially along each rib depending on the required distribution of deformations when making the double-curvature shape with specified parameters.

Let the arc length after folding the panel cross-section is

$$
A B=R_{c} \gamma^{\prime}=P-t / 2,
$$

whence in radians

$$
\gamma^{\prime}=\frac{P-t / 2}{R_{c}}
$$

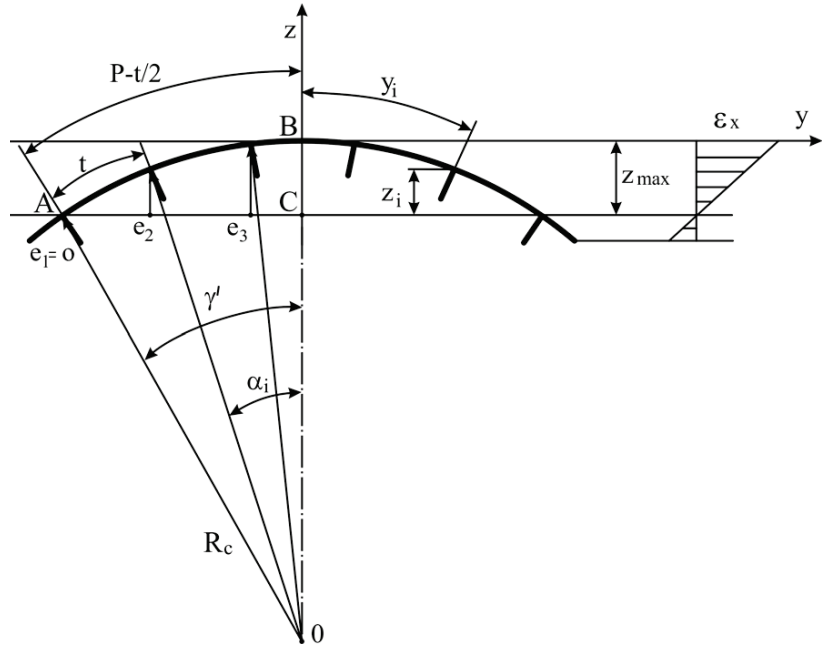

Fig. 5. Calculation diagram of flexural deformations of the panel ribs with formation of a double curvature:

$P$ is half the distance between the outermost ribs;

$t$ is the distance between the ribs; $y_{i}$ is the length of the arc of each rib; $Z_{i}$ is the coordinate of the rib relative to the neutral surface; $e_{i}$ is the flexural deformation at the point of intersection of the median surface of the sheet and the rib

The maximum height of flexure of the panel crosssection

$$
Z_{\max }=R_{c}-R_{c} \cdot \cos \gamma^{\prime}=R_{c}\left(1-\cos \gamma^{\prime}\right)
$$

The height of flexure of the $i$-th rib in the cross section

$$
\begin{aligned}
& Z_{i}=Z_{\max }-(O B-O C)= \\
& =R_{c}\left(1-\cos \gamma^{\prime}\right)-\left(R_{c}-R_{c} \cos \alpha_{i}\right)=R_{c}\left(\cos \alpha_{i}-\cos \gamma^{\prime}\right) .
\end{aligned}
$$

Consequently, the flexure deformation in the point of intersection of the median surface of the sheet and the rib is:

$$
\begin{aligned}
& e_{x}=\frac{Z_{i}}{R_{n}}=\frac{R_{c}}{R_{n}}\left(\cos \alpha_{i}-\cos \gamma^{\prime}\right)= \\
& =\frac{R_{c}}{R_{n}}\left(\cos \alpha_{i}-\cos \frac{P-t / 2}{R_{c}}\right),
\end{aligned}
$$

where

$$
\alpha_{i}=\frac{y_{i}}{R_{c}}
$$

It should be pointed out that $y_{\mathrm{i}}$ is measured on a flat panel.

Place the neutral surface in such a way that the outermost ribs do not deform, i. e. the neutral surface of the panel section passes through the points of intersection of the median of the panel surface and the axes of symmetry of the outermost edges. 

action

The magnitude of technological displacement at a single

$$
e=K S \text {, }
$$

where $K$ is the permissible relative deformation; $S$ is the size of the deformed part of the panel along the axis of the rib at a single technological action. The required design value of displacement along the axis of the rib at a single die action

$$
e=m_{i} \cdot \varepsilon_{i},
$$

where $m_{i}$ is the distance between two adjacent points of action on one rib.

Equate the calculated and technological displacements

$$
K S=m_{i} \cdot \varepsilon_{i}
$$

Taking into account expression (1), obtain

$$
m_{i}=\frac{K S}{\varepsilon_{i}}=\frac{K S R_{n}}{R_{c}} \frac{1}{\left(\cos \alpha_{i}-\cos \frac{P-t / 2}{R_{c}}\right)} .
$$

Similarly, when the panel is made by shrinking, the neutral surface will pass through point $B$. Then

$$
m_{i}=K \cdot S \cdot R_{n} \cdot\left(R_{c}-R_{c} \cos \alpha_{i}\right)^{-1}
$$

The energy of formation of curvature with radius $R_{c}$ is determined by the curvature of the sheet

$$
W_{b}^{t}=\frac{E h^{3}}{6 R_{c}^{2}} \cdot l \cdot p
$$

where $h$ is thickness of the panel sheet; $l$ is half the length of the panel.

The energy of formation of longitudinal curvature is determined by the curvature of the sheet together with the panel ribs.

Determine the energy of formation of longitudinal curvature from the equation given in work [10]. As a result, dependence for determining the energy of the calculated unit action is obtained:

$$
\begin{aligned}
& W_{i}^{t}=\frac{K S R_{p}}{L_{p}^{i} R_{c}}\left[\sum_{i=1}^{2 n}\left(\cos \frac{y_{i}}{R_{c}}-\cos \frac{P-t / 2}{R_{c}}\right)\right]^{-1} \times \\
& \times\left\{\frac{E h^{3}}{6 R_{c}^{2}} \cdot l \cdot p+\frac{E h^{3}}{24\left(1-v^{2}\right)} \int_{-l}^{l} \int_{-p}^{p}\left(a^{2}+2 v a b+b^{2}\right) d x d y+\right. \\
& \left.+\sum_{i=1}^{2 n} E\left[F_{p} e_{x}^{2}+I_{p}-2 e S_{p}\right] \int_{-l}^{l} b^{2} d x\right\} .
\end{aligned}
$$

This formula takes into account making of a double curvature in two stages. Formation of a transverse curvature with radius $R_{c}$ occurs in the first stage and a longitudinal curvature with radius $R_{n}$ is formed in the second stage.

\section{Results of experimental studies}

The number of elementary actions in accordance with the above procedure was found to be four on the middle rib of the sample and three on the adjacent ribs. The data of the actions were distributed evenly along the rib axes. Actions to the outermost ribs were applied as a bending moment sufficient to ensure longitudinal curvature of the panel. Following shaping, the panel samples were measured to check for shape changes relative to the initial state. An experimental study was conducted to determine accuracy of the resulting dimensions when bending panels with shrinking (stretching). The sample was placed horizontally on three adjustable supports and the height of each point was measured on a scribed grid with the help of V-630 cathetometer with an accuracy of \pm 40 microns.

Studies of the proposed technology were performed on $500 \times 1000 \mathrm{~mm}$ panel samples with $30 \mathrm{~mm}$ high ribs (Fig. 6).

On completion of deformation in accordance with the described procedure of distribution of local actions, samples had a smooth surface without faceting. Additional processing or cleaning of stretching areas on the panels was unnecessary. The places of shrinking required cleaning from the outside since protrusion of the material reached $0.05 \ldots 0.1 \mathrm{~mm}$ above the panel sheet level.

Minimum radii of longitudinal curvature of $6.5 \mathrm{~m}$ and a transverse curvature of $3 \mathrm{~m}$ were achieved in the specimens (Fig. 7).

Comparison of the obtained panel dimensions in three longitudinal and five cross sections showed that the maximum deviation upon applying the calculated actions was $1.48 \mathrm{~mm}$ for longitudinal sections and $1.67 \mathrm{~mm}$ for transverse sections. The deviations in the middle cross sections of the panels are shown in Fig. 8, 9.

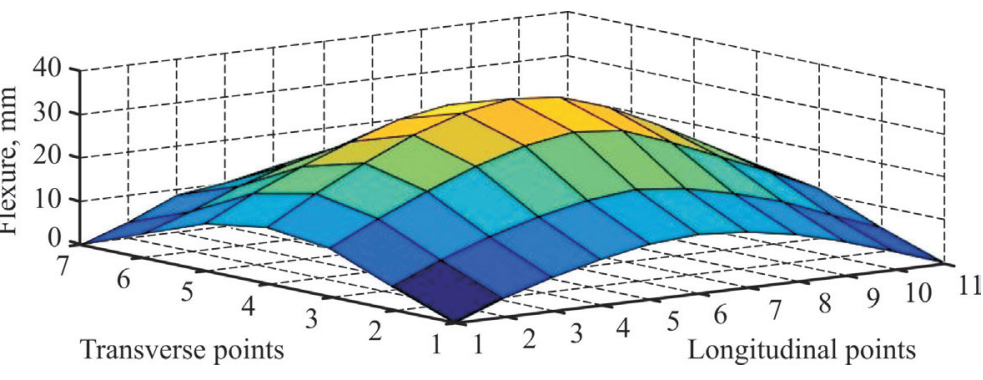

Fig. 6. Change in the shape of a double-curvature panel formed by the local bending method with stretching

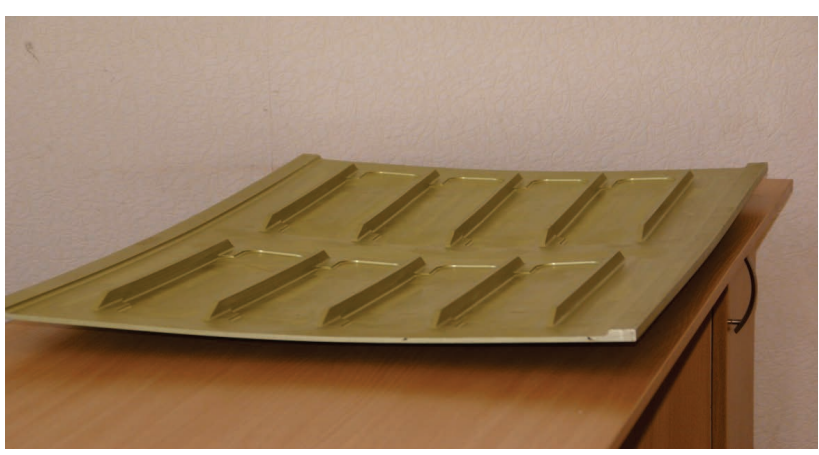

Fig. 7. A double-curvature panel with a complex internal engraving formed by the method of local bending with stretching 


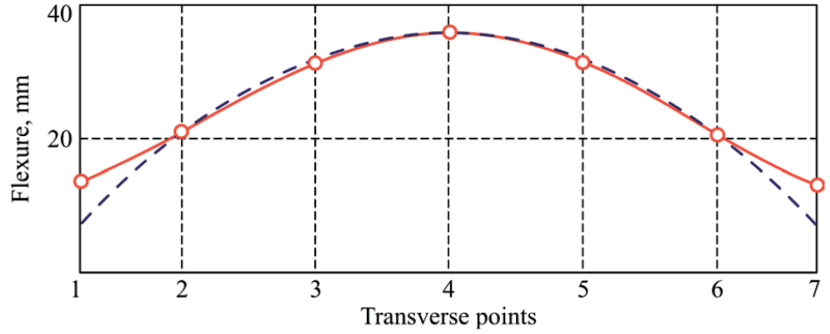

Fig. 8. Deviations of the heights of the panel points from the theoretical contour (cross-section 6-6, middle of the panel): $-0-1$ experimental values; - - - - - theoretical contour

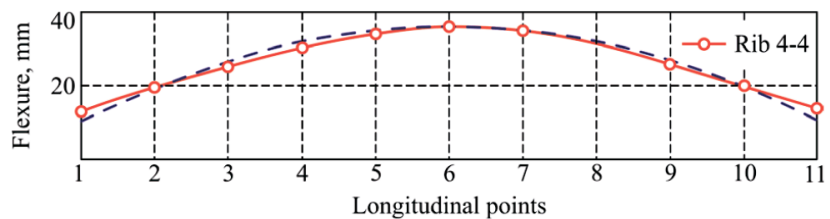

Fig. 9. Deviations of the heights of the panel points from the theoretical contour (longitudinal section $4-4$, middle of the panel): — - - experimental values; - - - - - theoretical contour

Deviations of the heights of the panel points from the horizontal for the outermost ribs (longitudinal section 2-2, 6-6) are shown in Fig. 10. Deviations have the same values and character as the deviations of the average panel sections which indicates a rather qualitative formation of the double curvature.

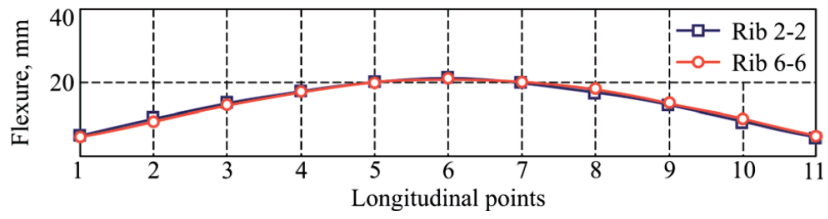

Fig. 10. Deviations of the heights of the panel points from the horizontal for the outermost ribs (longitudinal section $2-2,6-6$ )

Deviations of the heights of the panel points from the horizontal along the free edges (the longitudinal section 1-1, 7-7) are shown in Fig. 11. The magnitude of these deviations is important when assembling individual panels into a single structure.

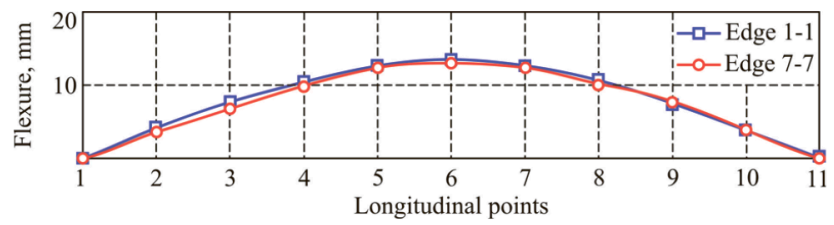

Fig. 11. Deviations of heights of the panel points from the horizontal along the free edges (longitudinal section $1-1,7-7$ )

As can be seen in Fig. 11, the nature of deviations of the free edges is very close to the nature of bending of the ribs and the magnitude of deviation of the ribs and free edges lies within the limits of deviations assigned to the shaping processes. Refinement actions were used to decrease shape deviations. Upon refinement, the surface shape had deviations up to $0.3 \mathrm{~mm}$ for longitudinal sections and up to $0.35 \mathrm{~mm}$ for transverse sections.

\section{Discussion of the results obtained in the study of forming monolithic panels}

By comparing $z$ coordinates of four corner points $1-1$, $1-7,11-1$ and $11-7$, it was found that the maximum difference in height between the corner points of the panel was $0.31 \mathrm{~mm}$. This allows us to conclude that in the manufacture of ribbed panels by the method of local bending with shrinking (stretching), twist has small values and does not lead to distortion of the panel shape. This twist can be easily compensated by elastic assembly of the structure.

The relative undulation of the outer surface of the panel in all sections (without taking into account the outermost points) has satisfactory values: no more than $1.5 \%$ for longitudinal sections and no more than $2 \%$ for transverse sections.

In some cases, to obtain the desired shape and dimensions of the panels, their edges require an additional shrinking, and a number of panel points require subsequent refinement for ribs and edges. The device makes it possible to bend individual ribs of the panel to small angles within $10 \ldots 20 \mathrm{~mm}$ which is very difficult to realize by other methods.

With the use of the successive wave processing of the cross sections and ribs, a double-curvature panel with the following geometric dimensions was obtained with the help of the device described above: the panel length: $5.5 \mathrm{~m}$, width: $1.1 \mathrm{~m}$, longitudinal radius: $12 \mathrm{~m}$, transverse radius: $1.5 \mathrm{~m}$ (Fig. 12).

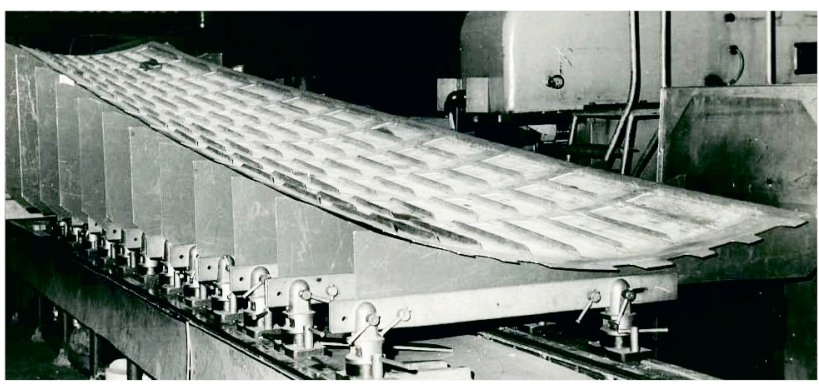

Fig. 12. The fuselage double-curvature panel obtained by stretching middle zones and bending

The panel has a variable cross-sectional thickness from 2.5 to $6.0 \mathrm{~mm}, 500-700 \mathrm{~mm}$ long slotted ribs and $6 \mathrm{~mm}$ thick free edges. The panel material is a high-strength aluminum alloy D16pchT.

The panel shaping was carried out by stretching of the middle zones in a die in accordance with the developed procedure for calculating the number of actions. The number of single actions along each rib of the panel is shown in Table 1.

Table 1

Number of single actions along each rib of the panel

\begin{tabular}{|c|c|c|c|c|c|c|c|c|c|}
\hline Rib order number & 1 & 2 & 3 & 4 & 5 & 6 & 7 & 8 & 9 \\
\hline $\begin{array}{l}\text { Number of actions applied } \\
\text { to the rib }\end{array}$ & 0 & 14 & 24 & 37 & 39 & 37 & 24 & 14 & 0 \\
\hline
\end{tabular}

After milling, the full-scale fuselage panels had characteristic geometric deviations of their face from flatness, a slight longitudinal and transverse curvature caused by generated and relieved residual stresses. Other minor geometrical deviations include a twist of the cross-section up to 5 degrees which can be eliminated by loading on a coordinate sizing bench and local surface irregularities. 
The panel surface roughness after milling and trimming with grinding machines was within $R_{a} 2.0-2.5$.

Elimination of local and general geometric deviations and deviations of the sheet thickness of the sheet before shaping was not required and was not carried out due to the specifics of the process. Experimental testing of various panel processing sequences showed that the panels had a stable shape independent of the deformation sequence. This rule is satisfied at small plastic deformations in the zone between the jaws of the shrinking device permissible for aluminum alloys.

Experimental studies of local deformation made it possible to formulate recommendations for making specific types of double-curvature panels which are presented in Table 2.

\section{Table 2}

Methods for obtaining double curvature panels by local deformation

\begin{tabular}{|c|c|c|c|}
\hline No. & $\begin{array}{c}\text { Types of } \\
\text { double-curva- } \\
\text { ture panels }\end{array}$ & $\begin{array}{c}\text { The panel sketch and } \\
\text { the law of deformation } \\
\text { for obtaining a double } \\
\text { curvature }\end{array}$ & $\begin{array}{l}\text { Preferable } \\
\text { manufacture } \\
\text { method }\end{array}$ \\
\hline 1 & Biconvex & & $\begin{array}{c}\text { Stretching } \\
\text { of the middle } \\
\text { zones according } \\
\text { to a certain law }\end{array}$ \\
\hline 2 & $\begin{array}{l}\text { Convexo- } \\
\text { concave }\end{array}$ & & $\begin{array}{c}\text { Stretching } \\
\text { of peripheral } \\
\text { zones + bending }\end{array}$ \\
\hline 3 & Biconcave & हx & $\begin{array}{c}\text { Shrinking } \\
\text { of peripheral } \\
\text { zones + bending }\end{array}$ \\
\hline 4 & $\begin{array}{l}\text { Concavo- } \\
\text { convex }\end{array}$ & $\mathrm{z} \uparrow^{\uparrow}$ & $\begin{array}{c}\text { Stretching } \\
\text { of middle } \\
\text { zones + bending }\end{array}$ \\
\hline
\end{tabular}

The shape of the panels shown in Table 2 can be obtained by the technique described above with the use of a die for local deformation. The procedure of distribution of local actions in formation of double curvature in the panel for the shown shapes remains unchanged if the neutral surface is located in accordance with the schemes shown in Table 2.

\section{Conclusions}

1. Equations were obtained for determining basic parameters of panel shaping depending on the required radii of curvature in the transverse and longitudinal directions. These parameters include the magnitude of energy of the local action in the direction of the rib axis and the number of actions along each rib. It was shown that the double curvature in the panel can be formed both by stretching (extension) and shrinking (contraction) of the rib sections along their axes.

2. Experimental studies of accuracy of the panel face shape showed that the maximum deviation after applying calculated actions was $1.48 \mathrm{~mm}$ for longitudinal sections and $1.67 \mathrm{~mm}$ for transverse ones. Separate deviations of the shape, for example, deviations of free edges and curvature near the ends of the ribs required refinement works after which the shape deviations did not exceed $0.3 \mathrm{~mm}$.

3 . The calculation procedure of the shaping process was tested on samples with regular and irregular structures including a complex internal engraving. Formation of the fuselage surface panel of a designed aircraft by medium-zone stretching in the die was also carried out in accordance with the proposed procedure for calculating the number of actions. In this case, the maximum deviation of the flexure height during formation of a double curvature did not exceed $7 \%$.

\section{References}

1. Verichev, S. N. Forming of monolithic stiffened double-curvature Panels of Aircraft Structures [Text] / S. N. Verichev, V. N. Maksimenko, S. V. Levyakov // Proceedings of 2009 International Forum on Strategic Technologies, 2009. - P. 185-187.

2. Sikulskiy, V. T. Forming of monolithic panels of complex shapes [Text] / V. T. Sikulskiy // Aerospace engineering and technology. 2013. - Vol. 5-102. - P. 15-19.

3. Oleinikov, A. I. Integrated design of monolithic panel manufacturing processes [Text] / A. I. Oleinikov, A. I. Pekarsh. - Moscow: Ecom, 2009. - 112 p.

4. Yu, Y. FEM modelling for press bend forming of doubly curved integrally stiffened aircraft panel [Text] / Y. Yan, H. Wang, M. Wan // Transactions of Nonferrous Metals Society of China. - 2012. - Vol. 22. - P. s39-s47. doi: 10.1016/s1003-6326(12)61681-1

5. Yue, F. Knowledge base research on the incremental press bending technology of the integral wing-skin panel [Text] / F. Yue, J. Liu, S. Zhang, Y. Zeng // Materials Science and Technology. - 2008. - Vol. 16, Issue 3. - P. 306-309.

6. Pashkov, A. E. Technological complex for the formation of long-length panels and plating on the basis of domestic equipment [Text] / A. E. Pashkov // Izvestiya of the Samara Scientific Center of the Russian Academy of Sciences. - 2014. - Vol. 16, Issue 1 (5). P. $1528-1536$.

7. Yu, Y. Prediction of stiffener buckling in press bend forming of integral panels [Text] / Y. Yan, H. Wang, M. Wan // Transactions of Nonferrous Metals Society of China. - 2011. - Vol. 21, Issue 11. - P. 2459-2465. doi: 10.1016/s1003-6326(11)61037-6

8. Dragobetskii, V. V. Development of Elements of Personal Protective Equipment of New Generation on the Basis of Layered Metal Compositions [Text] / V. V. Dragobetskii, A. A. Shapoval, V. G. Zagoryanskii // Steel in Translation. - 2015. - Vol. 45, Issue 1. P. 33-37. doi: 10.3103/s0967091215010064

9. Sikulskiy, V. T. Shaping of panels with longitudinal finning of local flexible with planting (wiring) [Text] / V. T. Sikulskiy // Bulletin of the National Technical University «Kharkov Polytechnic Institute». - 2014. - Vol. 5, Issue 1048. - P. 73-80.

10. Sikulskiy, V. T. Calculation of the basic parameters of symmetrical shaping of monolithic ribbed panels of double curvature by successive deformation [Text] / V. T. Sikulskiy, M. E. Taranenko, V. Yu. Kashcheeva, S. V. Sikulskyi // Processing of materials by pressure. - 2017. - Vol. 1, Issue 44. - P. 143-148. 